\title{
Predictive value of survivin alternative transcript expression in locally advanced breast cancer patients treated with neoadjuvant chemotherapy
}

\author{
ROMAIN BOIDOT $^{1}$, FRÉDÉRIQUE VEGRAN ${ }^{1,2}$ and SARAB LIZARD-NACOL ${ }^{1}$ \\ Centre Georges François Leclerc, Molecular Biology Unit, IFR Santé-STIC, Dijon, France
}

Received October 3, 2008; Accepted December 2, 2008

DOI: 10.3892/ijmm_00000129

\begin{abstract}
Survivin, a member of the apoptosis inhibitor protein family, is expressed in numerous human tumours, and its expression is described as a negative prognostic marker. Four alternative splice variants (survivin- $\Delta \mathrm{Ex} 3$, survivin-3B, survivin-2B and survivin- $2 \alpha$ ) have been described. To date, little is known about the prognostic or predictive role of all five survivin transcripts in breast cancer. In this study, we analysed, by means of real-time quantitative PCR, the five survivin transcripts in a population of 60 breast carcinoma patients treated with 5-fluorouracil + epirubicin + cyclophosphamide (FEC, $n=32$ ) or with docetaxel + epirubicin (Tax-Epi, n=28). For each patient, samples were obtained before and after one course of chemotherapy. Before treatment, the ratio of survivin- $2 \alpha$ was significantly higher in resistant than in sensitive tumours treated by the FEC regimen $(\mathrm{p}=0.0161)$, while the ratio of survivin- $\Delta \mathrm{Ex} 3$ was higher in sensitive than in resistant samples treated with Tax-Epi $(p=0.0234)$. After one course of chemotherapy, expression of survivin-3B was significantly associated with resistance $(\mathrm{p}=0.0448)$ in the FEC treatment group, and the ratios of survivin- $\Delta \mathrm{Ex} 3(\mathrm{p}=0.0071)$ and survivin-2B $(\mathrm{p}=0.0380)$ were significantly higher in sensitive than in resistant tumours in the Tax-Epi treatment group. Notably, increased expression and ratio of survivin-3B after one course of Tax-Epi was associated with reduced disease-free survival ( $\mathrm{p}=0.0299$ and 0.0277 , respectively) and with reduced overall survival ( $p=0.0145$ and $<0.0001$, respectively) of the patients. These results indicate that an imbalance in the alternative transcript ratios may make the cells resistant or sensitive to apoptosis. They also demonstrate for the first time that alternative
\end{abstract}

Correspondence to: Dr Sarab Lizard-Nacol, Laboratory of Molecular Genetics, Centre Georges François Leclerc, 1 rue du Professeur Marion, 21034 Dijon Cedex, France

E-mail: slizard@dijon.fnclcc.fr

Present address: ${ }^{2}$ Unit of Pharmacology and Therapeutics, University of Louvain Medical School, Brussels, Belgium

Key words: breast cancer, neoadjuvant chemotherapy, survivin, splice variants, expression, response survivin transcript expression levels may be predictive markers in FEC and Tax-Epi treatment in breast carcinoma.

\section{Introduction}

In adult tissues, apoptosis participates in homeostasis and assures the stability of tissue integrity. An imbalance between pro-apoptotic elements such as caspases and anti-apoptotic genes such as inhibitors of apoptosis proteins (IAP) can inhibit apoptosis or activate it. The inhibition of apoptosis is one of the main mechanisms implied in cancer generation.

Survivin is the smallest member of the IAP family and is periodically expressed during the cell cycle; undetectable in phase $\mathrm{G} 1$, its expression is multiplied by 6 in phase $\mathrm{S}$ and by more than 40 in G2/M $(1,2)$. Survivin is expressed in foetal tissues and regulated in a developmentally dependent manner $(3,4)$. Survivin is not expressed in human adult tissues but is re-expressed in numerous cancers such as breast, colon and lung (1).

By alternative splicing, the survivin gene encodes 5 transcripts. The main transcript is survivin which is formed by the 4 exons for a length of $431 \mathrm{nt}$. This transcript encodes a $17-\mathrm{kDa}$ protein possessing a BIR (Bacculovirus IAP repeat) domain responsible for its anti-apoptotic functions (5). Survivin inhibits extrinsic and intrinsic apoptotic pathways (6) by direct or indirect interactions with caspases-3, -7 and -9 (7-9). Survivin is necessary for mitosis especially in G2/M transition (2). This protein controls chromosome compaction and mitotic spindle formation and regulates microtubule dynamics (10).

Survivin- $\Delta \mathrm{Ex} 3$, with a length of $329 \mathrm{nt}$, results from the skipping of exon 3 which leads to a loss of $102 \mathrm{bp}$ and a frameshift. Survivin- $\Delta \mathrm{Ex} 3$ protein, with a molecular weight of $15.9 \mathrm{kDa}$, engages in the same anti-apoptotic activities as survivin although no role in the cell cycle has been identified (11-14). Survivin-2B results from the introduction of a new 69-bp exon called exon $2 \mathrm{~B}$, which is part of intron 2 (11). The survivin-2B protein, with a molecular weight of $18.5 \mathrm{kDa}$, possesses a truncated BIR domain but is believed to have proapoptotic functions with no evidence for a role in cell cycle regulation (15). Survivin-3B includes a 165-nt part of intron 3 corresponding to exon 3B. Survivin-3B may have a molecular weight of $12.5 \mathrm{kDa}$. This variant is unable to interact either with tubulin or with chromosomes and may have no role in cell cycle regulation. Moreover, survivin-3B possesses a 
complete BIR domain and therefore a potential anti-apoptotic activity (16). Survivin- $2 \alpha$ corresponds to the introduction of $197 \mathrm{nt}$ of the 3 ' terminus part of intron 2 . This inclusion results in an early stop codon just before exon 3 , giving rise to the shortest survivin variant. Survivin- $2 \alpha$ does not possess the BIR domain, and it seems to have an antagonistic activity in relation to survivin (17).

Numerous studies have explored survivin expression in many types of cancer, but most of them have focused on the main survivin transcript. Deregulated survivin expression has been reported at both the mRNA and protein levels. Survivin mRNA overexpression has been described as a negative prognostic marker in breast cancer $(18,19)$. At the protein level, survivin is localised to the nucleus and cytoplasm or both, and a number of studies have implied that differences in patient prognosis correlate with differences in nuclear or cytoplasmic compartmentalisation (20-22). It has been reported that cytoplasmic survivin is associated with a poor prognosis (23), whereas nuclear survivin was a significant independent prognostic indicator of favourable outcome in both the disease-free and overall survival of breast cancer patients (24). Recently, nuclear survivin was reported to be a poor prognostic marker in breast cancer (25). Thus, no clear consensus emerges from these studies.

To date, very little is known about the prognostic or predictive role of all five survivin transcripts in breast cancer. One study analysing three of the survivin transcript expression levels showed a lack of prognostic significance of survivin, survivin- $\Delta \mathrm{Ex} 3$ and survivin-2B (26). In another study, the level of both survivin and survivin- $\Delta \mathrm{Ex} 3$ but not survivin- $2 \mathrm{~B}$ was found to correlate significantly with apoptosis (27). To date, only one study has analysed the five survivin transcripts in breast carcinomas. However, the amplicon amplified for survivin-wt was not representative of this transcript, since it localised on exon 1, a region that is common to all transcripts (28). In the present study, we investigated the predictive values of the five transcripts individually in locally advanced breast cancer patients treated by neoadjuvant chemotherapy.

\section{Materials and methods}

Patients and samples. We studied a series of 60 patients with non-metastatic large-tumour, unilateral, non-inflammatory, operable breast cancer requiring mastectomy (but who wished to conserve the breast) treated with neoadjuvant chemotherapy between 1999 and 2000 at the anticancer centres in Dijon, Reims, Nancy and Strasbourg, France, and enrolled in a multicenter, phase II GIREC 01 trial (29). Criteria for the selection of these patients included the availability of tumour tissue from biopsies removed before and after one cycle of chemotherapy for mRNA analysis. Of these patients, 32 received 5-fluorouracil-epirubicin-cyclophosphamide (FEC): 5-fluorouracil $\left(500 \mathrm{mg} / \mathrm{m}^{2}\right)$, epirubicin $\left(100 \mathrm{mg} / \mathrm{m}^{2}\right)$ and cyclophosphamide $\left(500 \mathrm{mg} / \mathrm{m}^{2}\right)$ (6 courses every 21 days $)$. The remaining 28 patients received docetaxel-epirubicin (Tax-Epi) treatment: docetaxel $\left(75 \mathrm{mg} / \mathrm{m}^{2}\right)$ and epirubicin $\left(100 \mathrm{mg} / \mathrm{m}^{2}\right)$ (6 courses every 21 days).

Response evaluation. Assessment of histological response (HR) in the surgical specimens was based on a classification proposed by Sataloff et al (30). This classification allows the evaluation of the extent of therapeutic effect on the primary tumour site and axillary lymph nodes. HR was graded as complete if a total or near total therapeutic effect on the tumour and negative nodes were present. Carcinomas were classified as partially resistant to the treatment if a $>50 \%$ therapeutic effect on the tumour and negative or positive nodes with the therapeutic effect were present. Carcinomas were classified as resistant to the treatment if a $<50 \%$ therapeutic effect in the tumour, regardless of node status, was present. In the FEC subset, patients with complete ( 5 cases) or partial (9 cases) histological response were classified as sensitive (14 cases) and patients with no histological response (18 cases) were classified as resistant to chemotherapy. In the Tax-Epi group, the same classification was used, resulting in 7 complete and 9 partial histological responses (16 sensitive tumours) and 12 subjects with no histological response to this regimen.

All tissue samples, taken before and after one course of chemotherapy, were frozen and stored in liquid nitrogen. A needle core biopsy was performed for initial diagnosis and two more were designed for RNA extraction. All biopsies were controlled for tumour cell frequencies by a pathologist after HES staining. Only cases with at least $30 \%$ of tumour cells were studied. This research was carried out with the approval of the local boards governing research on human subjects. Total RNA from a pool of 4 normal mammary tissues (NMT) was purchased from Clontech (Palo Alto, CA) and was used as a normal sample.

RNA extraction and cDNA synthesis. Total RNA was extracted from the needle core biopsies by using the Qiagen ${ }^{\circledR}$ RNA/ DNA Mini Kit (Qiagen, Hilden, Germany) or the TRIzol ${ }^{\circledR}$ Reagent (Invitrogen, Carlsbad, CA, USA). The quantity and purity of RNA were assessed spectrophotometrically at 260 and $280 \mathrm{~nm}$ (the $\mathrm{A}_{260} / \mathrm{A}_{280}$ ratio of pure RNA is $>1.8$ ). The quality of RNA extracts was determined by electrophoresis through agarose gel, staining with ethidium bromide, and visualisation of the $18 \mathrm{~S}$ and $28 \mathrm{~S}$ bands under UV light. One microgram of total RNA was reverse transcribed in $20 \mu \mathrm{l}$ of reverse transcriptase reaction as previously described (31).

Quantitative RT-PCR. Real-time quantitative PCR was performed on ABI PRISM 7300 (Applied Biosystems, Foster City, CA, USA) by using the Taqman ${ }^{\circledR}$ method. As we analysed tumours before and after one course of chemotherapy, we tested expression variation in 4 housekeeping genes (18S, GAPDH, ß-actin and TBP). Of these 4 genes, $18 \mathrm{~S}$ was the only gene that was stable after one course of chemotherapy. The analysis of the $18 S$ gene was thus used to assess cDNA quality and served as the reference control gene.

The nucleotide sequences of primers and probes for the $18 S$ gene and survivin transcripts, as well as the location of primers and probes for survivin transcripts have been described previously (34).

The probes were labelled at the 5 ' end with VIC for the $18 S$ gene or FAM for survivin transcripts, and at the $3^{\prime}$ end with Tamra. Amplification was performed in a total volume of $25 \mu \mathrm{l}$ in the presence of $12.5 \mu \mathrm{l}$ of Universal Master Mix (Applied Biosystems), $80 \mathrm{nM}$ of each primer and $50 \mathrm{nM}$ of probe for the $18 \mathrm{~S}$ gene, $150 \mathrm{nM}$ primers and $200 \mathrm{nM}$ probe 

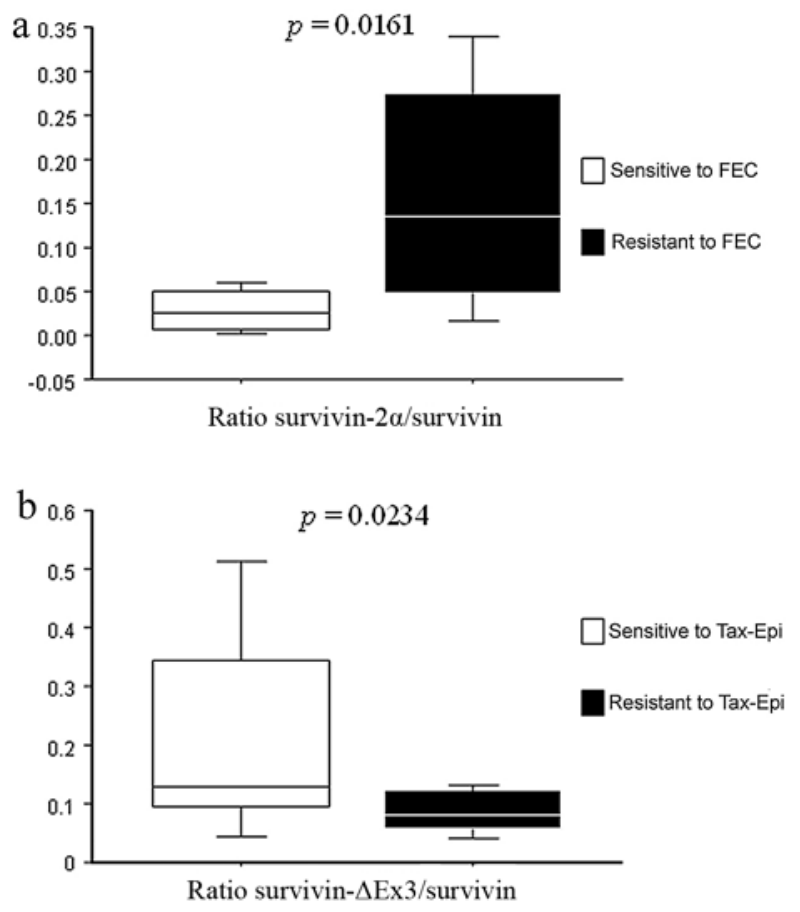

Figure 1. Distribution and comparison of survivin variant ratio expression in tumours analysed before treatment according to histological response. (a) Survivin-2 $\alpha$ /survivin ratio was significantly correlated with response to FEC. (b) Survivin- $\Delta E x 3 /$ survivin ratio was significantly correlated with response to Tax-Epi treatment.

for survivin, $300 \mathrm{nM}$ primers and $150 \mathrm{nM}$ probe for survivin$\Delta \mathrm{Ex} 3,300 \mathrm{nM}$ primers and $200 \mathrm{nM}$ probe for survivin-2B, $300 \mathrm{nM}$ primers and $150 \mathrm{nM}$ probe for survivin-3B, $600 \mathrm{nM}$ primers and $200 \mathrm{nM}$ probe for survivin- $2 \alpha$, and $12.5 \mathrm{ng}$ of cDNA (or water as a negative control). The PCR program consisted of a 10-min initial denaturation step at $95^{\circ} \mathrm{C}$, followed by 40 cycles of $15 \mathrm{sec}$ at $95^{\circ} \mathrm{C}$ and $1 \mathrm{~min}$ at $60^{\circ} \mathrm{C}$. The specificity of the $18 \mathrm{~S}$ and survivin PCR amplifications was verified by the sequencing of PCR products. The quality of PCR primers was verified by assessing the amplification efficiency on a standard curve established with the MCF-7 cell line. Amplification efficiency was measured in the range of $98 \%( \pm 1 \%)$. All samples were amplified in duplicate, and results were analysed by the $2^{-\Delta \mathrm{Ct}}$ method (32).

Statistical analysis. All analyses were performed with Statview 5.0 software. Histological response was correlated with survivin transcript expression and variations using the MannWhitney U test. The overall survival (OS) was defined as the interval between the diagnosis and the last follow-up or death. Disease-free survival (DFS) was defined as the time between the date of diagnosis and the date of distant metastases or local recurrence or death, whichever came first, or the last follow-up. Survival curves were generated using the Kaplan and Meier method, and the significance of differences between dichotomized patient groups was obtained by the Mantel-Cox $\log$ rank test. Dichotomization of the patient groups was carried out according to the median level of survivin transcripts in each treatment subset. Only tests with $\mathrm{p}<0.05$ were considered significant.
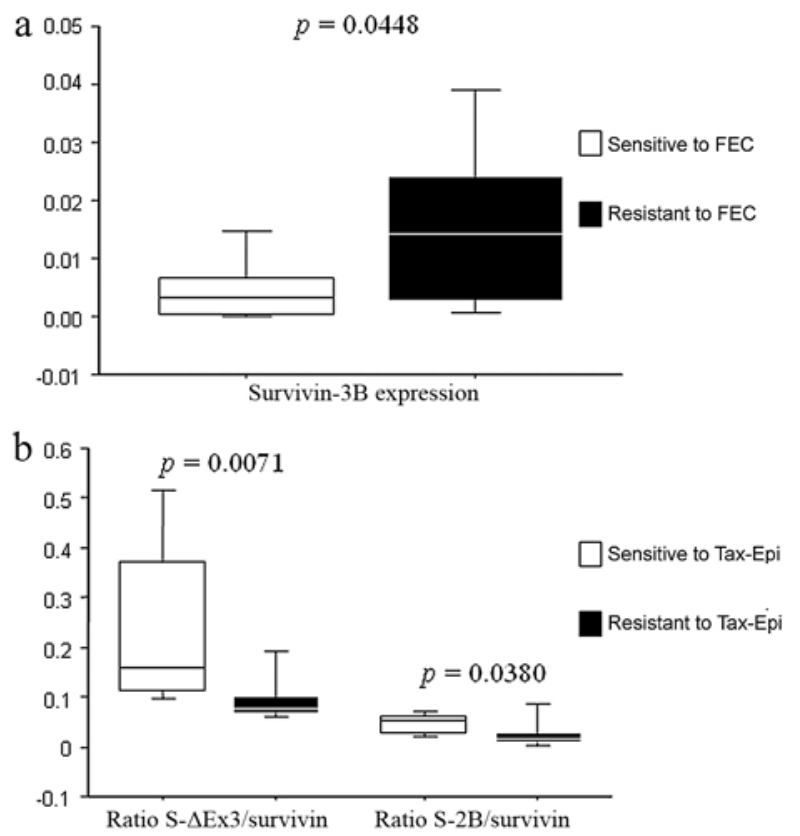

Figure 2. Distribution and comparison of survivin variant expression or ratio in tumours analysed after one course of chemotherapy according to histological response. (a) Survivin-3B expression was significantly lower in responders to FEC treatment. (b) In Tax-Epi-treated tumours, an increase in the survivin- $\Delta \mathrm{Ex} 3 /$ survivin or the survivin-2B/survivin ratio was correlated with a favourable response.

\section{Results}

Survivin expression and histological response in tumours analysed before treatment. In the entire population, survivin and survivin- $2 \alpha$ expression was detected in all samples before treatment $(100 \%)$; survivin- $\Delta \mathrm{Ex} 3$ in $54 / 55$ (98\%), survivin$3 \mathrm{~B}$ in $43 / 52(83 \%)$, and survivin-2B in 53/55 (96\%) samples. Correlations between the five survivin transcript expression levels and histological response to FEC or Tax-Epi treatment revealed no significant links. As the ratio between alternative transcripts and the main transcript of a gene could influence cell response to apoptosis (33), ratios between each variant and survivin were explored. The ratio of survivin-2 $\alpha$ was significantly higher in resistant than in sensitive tumours treated with the FEC regimen (Fig. 1a), while the ratio of survivin$\triangle \mathrm{Ex} 3$ was higher in sensitive than in resistant samples treated with Tax-Epi (Fig. 1b).

Survivin expression and histological response in tumours obtained after one course of chemotherapy. After one course of chemotherapy, survivin, survivin- $\Delta \mathrm{Ex} 3$ and survivin- $2 \alpha$ transcripts were present in all tumours; survivin-3B in $30 / 38$ (79\%), and survivin-2B in 40/42 (95\%). In the FEC treatment group, expression of survivin-3B was significantly associated with resistance (Fig. 2a). In the Tax-Epi treatment group, the ratios of survivin- $\Delta \mathrm{Ex} 3$ and survivin-2B were significantly higher in sensitive than in resistant tumours (Fig. 2b).

Expression variations between non-treated (NT) and chemotherapy-treated (TT) tumours and response to chemotherapy. We investigated the correlation between the variations in 
Table I. Details of events for disease-free and overall survival of the studied breast cancer patients.

\begin{tabular}{|c|c|c|c|c|c|}
\hline \multirow{2}{*}{$\begin{array}{l}\text { Patient } \\
\text { no. }\end{array}$} & \multirow{2}{*}{ Treatment } & \multicolumn{2}{|c|}{ Disease-free survival } & \multicolumn{2}{|c|}{ Overall survival } \\
\hline & & Months & Events & Months & Events \\
\hline 1 & FEC & 56.4 & Non-censured & 62.4 & Non-censured \\
\hline 2 & FEC & 72.0 & Censured & 72.0 & Censured \\
\hline 3 & FEC & 62.4 & Non-censured & 74.4 & Censured \\
\hline 4 & FEC & 13.2 & Non-censured & 13.2 & Non-censured \\
\hline 5 & FEC & 12.0 & Non-censured & 20.4 & Non-censured \\
\hline 6 & FEC & 84.0 & Censured & 84.0 & Censured \\
\hline 7 & FEC & 79.2 & Censured & 79.2 & Censured \\
\hline 8 & FEC & 84.0 & Censured & 84.0 & Censured \\
\hline 9 & FEC & 30.0 & Non-censured & 36.0 & Non-censured \\
\hline 10 & FEC & 51.6 & Non-censured & 72.0 & Censured \\
\hline 11 & FEC & 64.8 & Non-censured & 76.8 & Censured \\
\hline 12 & FEC & 28.8 & Non-censured & 60.0 & Non-censured \\
\hline 13 & FEC & 60.0 & Censured & 60.0 & Censured \\
\hline 14 & FEC & 67.2 & Non-censured & 68.4 & Non-censured \\
\hline 15 & FEC & 84.0 & Censured & 84.0 & Censured \\
\hline 16 & FEC & 85.2 & Censured & 85.2 & Censured \\
\hline 17 & FEC & 84.0 & Censured & 84.0 & Censured \\
\hline 18 & FEC & 80.0 & Censured & 80.0 & Censured \\
\hline 19 & FEC & 51.0 & Non-censured & 72.0 & Censured \\
\hline 20 & FEC & 72.0 & Censured & 72.0 & Censured \\
\hline 21 & FEC & 91.0 & Censured & 91.0 & Censured \\
\hline 22 & FEC & 29.0 & Non-censured & 35.0 & Non-censured \\
\hline 23 & FEC & 60.0 & Censured & 60.0 & Censured \\
\hline 24 & FEC & 55.0 & Non-censured & 63.0 & Non-censured \\
\hline 25 & FEC & 87.0 & Censured & 87.0 & Censured \\
\hline 26 & FEC & 61.0 & Censured & 61.0 & Censured \\
\hline 27 & FEC & 85.0 & Censured & 85.0 & Censured \\
\hline 28 & FEC & 69.0 & Censured & 69.0 & Censured \\
\hline 29 & FEC & 30.0 & Non-censured & 54.0 & Non-censured \\
\hline 30 & FEC & 67.0 & Censured & 67.0 & Censured \\
\hline 31 & FEC & 50.0 & Non-censured & 89.0 & Censured \\
\hline 32 & FEC & & & $\mathrm{n} / \mathrm{a}$ & \\
\hline 33 & Tax-Epi & 67.2 & Non-censured & 79.2 & Censured \\
\hline 34 & Tax-Epi & 84.0 & Censured & 84.0 & Censured \\
\hline 35 & Tax-Epi & 78.0 & Censured & 78.0 & Censured \\
\hline 36 & Tax-Epi & 84.0 & Censured & 84.0 & Censured \\
\hline 37 & Tax-Epi & 51.6 & Non-censured & 80.4 & Non-censured \\
\hline 38 & Tax-Epi & 32.4 & Non-censured & 36.0 & Non-censured \\
\hline 39 & Tax-Epi & 38.4 & Non-censured & 78.0 & Non-censured \\
\hline 40 & Tax-Epi & 91.2 & Censured & 91.2 & Censured \\
\hline 41 & Tax-Epi & 21.6 & Non-censured & 36.0 & Non-censured \\
\hline 42 & Tax-Epi & 61.0 & Censured & 61.0 & Censured \\
\hline 43 & Tax-Epi & 60.0 & Censured & 60.0 & Censured \\
\hline 44 & Tax-Epi & 84.0 & Censured & 84.0 & Censured \\
\hline 45 & Tax-Epi & 26.4 & Non-censured & 48.0 & Non-censured \\
\hline 46 & Tax-Epi & 90.0 & Censured & 90.0 & Censured \\
\hline 47 & Tax-Epi & 41.0 & Non-censured & 62.0 & Non-censured \\
\hline 48 & Tax-Epi & 70.0 & Censured & 70.0 & Censured \\
\hline 49 & Tax-Epi & 45.0 & Non-censured & 50.0 & Censured \\
\hline 50 & Tax-Epi & 90.0 & Censured & 90.0 & Censured \\
\hline 51 & Tax-Epi & 76.0 & Censured & 76.0 & Censured \\
\hline 52 & Tax-Epi & 39.0 & Non-censured & 65.0 & Non-censured \\
\hline
\end{tabular}

Table I. Continued.

\begin{tabular}{|c|c|c|c|c|c|}
\hline \multirow{2}{*}{$\begin{array}{l}\text { Patient } \\
\text { no. }\end{array}$} & \multirow[t]{2}{*}{ Treatment } & \multicolumn{2}{|c|}{ Disease-free survival } & \multicolumn{2}{|c|}{ Overall survival } \\
\hline & & Months & Events & Months & Events \\
\hline 53 & Tax-Epi & 88.0 & Censured & 88.0 & Censured \\
\hline 54 & Tax-Epi & 78.0 & Censured & 78.0 & Censured \\
\hline 55 & Tax-Epi & 83.0 & Censured & 83.0 & Censured \\
\hline 56 & Tax-Epi & 66.0 & Non-censured & 69.0 & Censured \\
\hline 57 & Tax-Epi & 73.0 & Censured & 73.0 & Censured \\
\hline 58 & Tax-Epi & 82.0 & Censured & 82.0 & Censured \\
\hline 59 & Tax-Epi & & & $\mathrm{n} / \mathrm{a}$ & \\
\hline 60 & Tax-Epi & & & $\mathrm{n} / \mathrm{a}$ & \\
\hline
\end{tabular}

$\mathrm{n} / \mathrm{a}$, not available.

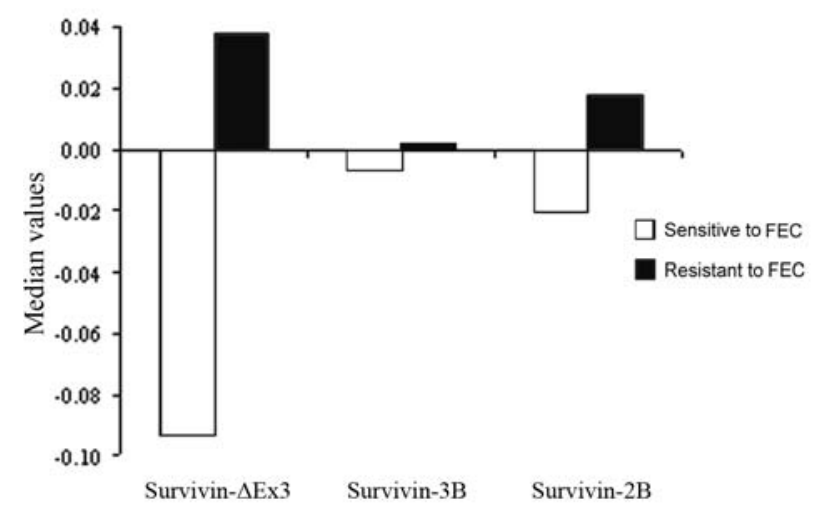

Figure 3. Variations of survivin alternative transcripts after one course of chemotherapy in the FEC treatment group. The values were obtained by subtraction of survivin transcript expression in chemotherapy-treated (TT) tumours by survivin transcript expression in non-treated (NT) tumours. Positive values correspond to overexpression and negative values to a decrease in expression. Decrease in survivin- $\Delta E x 3$, survivin-3B or survivin2B expression was highly correlated with response ( $\mathbf{(})$ in comparison to no response ( $\square$ ).

survivin transcript expression levels in tumours analysed before and after one course of chemotherapy and the histological response. The results revealed that a decrease in survivin- $\Delta \mathrm{Ex} 3$, survivin-3B and survivin- $2 \mathrm{~B}$ after one course of FEC chemotherapy was statistically related with responsive tumours, whereas an increase in this transcript expression was associated with no response $(\mathrm{p}=0.0070,0.0164$ and 0.0129, respectively) (Fig. 3).

Increased expression of survivin-3B after one course of TaxEpi treatment is associated with both disease-free and overall survival in patients. All survivin transcript expression and ratios were analysed before and after one course of treatment according to patient survival (Table I). The median disease-free survival (DFS) was 64.8 months (range 12-91) for FEC and 71.5 (21.6-91.2) for Tax-Epi treatment. The median overall survival (OS) was 72 months (13.2-91) in the FEC and 78 (36-91.2) in the Tax-Epi group. Details of censured and non-censured events are presented in Table I. 
Values after one course of Tax-Epi treatment
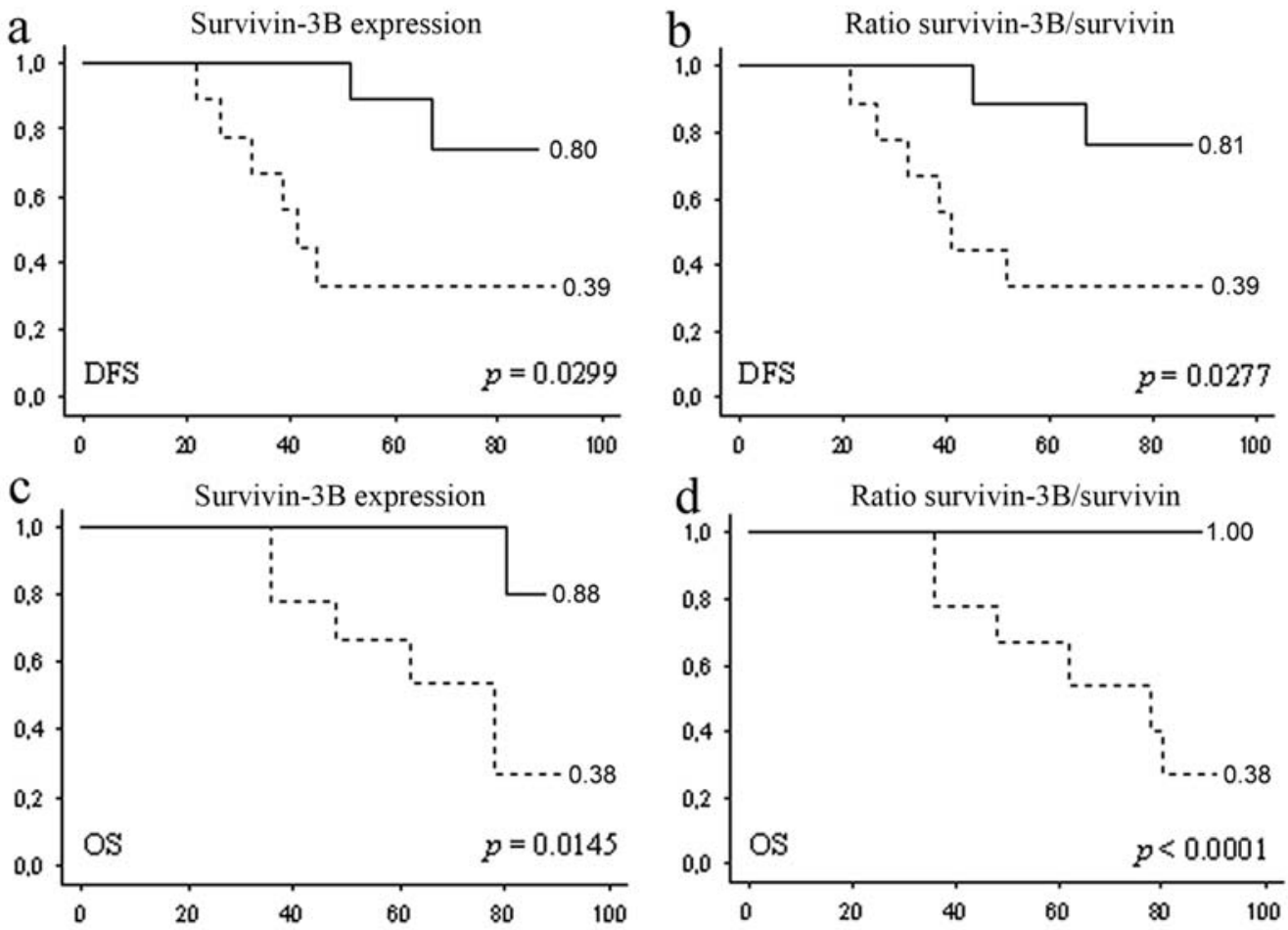

Figure 4. Correlation of survivin-3B expression and its ratio in tumours analysed after one course of Tax-Epi treatment with disease-free survival (DFS) and overall survival (OS). Patients with survivin-3B expression (a) or ratio (b) inferior to median values (solid line) had an increased DFS than patients with superior values (dotted line). Identical findings were obtained for survivin-3B expression (c) or ratio (d) and OS.

Before treatment, no relations were found between survivin transcript expression or ratios and DFS or OS in either the FEC or the Tax-Epi group. After one course of treatment neither survivin transcripts nor ratios were correlated with any survival in patients of the FEC group. In contrast, in the Tax-Epi group, survivin-3B expression and ratio were significantly associated with DFS and OS. Patients with high survivin-3B expression or ratio showed a reduced survival $(\mathrm{p}=0.0299$ and 0.0277 , respectively) (Fig. 4a). The same findings were obtained for overall survival ( $\mathrm{p}=0.0145$ and $<0.0001$, respectively) (Fig. 4b).

\section{Discussion}

In this study, five of the survivin transcripts were specifically analysed at the mRNA level by means of quantitative RT-PCR in breast tumours sampled before chemotherapy and in samples obtained after one course of FEC or Tax-Epi regimen. Our results revealed that ratios between alternative transcripts and survivin were significantly associated with histological response. In the FEC group, the survivin-2 $\alpha$ /survivin ratio was higher in resistant tumours, suggesting for the first time that survivin- $2 \alpha$ may be involved in resistance to FEC treatment. This result may be consistent with the finding that survivin can heterodimerise with its splice variants causing specific subcellular localisation patterns leading to formation of the functionally distinct survivin complex (12).

In the Tax-Epi subset, the survivin- $\Delta \mathrm{Ex} 3 /$ survivin ratio was associated with sensitivity, suggesting that high expression of this variant may sensitise tumours to a docetaxel-based regimen. As survivin- $\Delta \mathrm{Ex} 3$ is a nuclear protein (34) and docetaxel acts on microtubules in the cytoplasm (35), survivin- $\Delta \mathrm{Ex} 3$ is unable to protect cells from docetaxel-mediated cytoplasm aggressions.

Our study showed that increased survivin transcript expression or ratios after one course of chemotherapy were also linked to the histological response. After one course of FEC treatment, survivin-3B was overexpressed in resistant tumours, suggesting that survivin-3B could be useful in determining, after one course of FEC, whether patients are sensitive to the treatment. These data are in accordance with the putative anti-apoptotic function of survivin-3B (16) and may corroborate a recent study describing survivin- $3 \mathrm{~B}$ as a cytoprotective protein (36).

In both samples taken before and after one course of TaxEpi chemotherapy, the survivin- $\Delta \mathrm{Ex} 3 /$ survivin ratio indicated significantly higher expression in sensitive than in resistant tumours. Moreover, after one course of Tax-Epi treatment, a high survivin-2B/survivin ratio was statistically associated with tumour sensitivity. This latter result is in accordance with most studies describing survivin-2B with a pro-apoptotic function $(11,15)$. Notably, a recent study demonstrated that forced expression of survivin-2B sensitises cells to taxolinduced cell growth inhibition and cell death (37). However, new alternative transcripts of survivin have been described recently (38). Among the primers and probes we used in the present study, only detection of the survivin-2B transcript could be influenced by the presence of the newly described 
survivin transcripts. Nevertheless, the expression of these transcripts has not yet been proven in breast carcinoma.

Before treatment, neither survivin transcript expression nor ratio was correlated with DFS or OS in any group. However, after one course of treatment, both survivin-3B expression and ratio were significantly associated with reduced DFS and OS in Tax-Epi-treated patients. Thus, it is important to determine the mechanisms by which survivin-3B could be implicated in the resistance to Tax-Epi treatment.

Our study characterised for the first time the predictive value of survivin variants and their ratios in breast cancer patients treated with specific regimens. Our results further showed that expression variations could be important for response prediction, since observed variations between samples taken before and after chemotherapy were significantly associated with sensitivity or resistance to chemotherapy.

In conclusion, the present study demonstrated that survivin transcript ratios were informative in predicting histological response to FEC or Tax-Epi treatments. This finding may reflect previous studies demonstrating that an imbalance in the alternative transcript ratios may make cells resistant or sensitive to apoptosis (33). Based on our results, it is necessary to study a large population of breast carcinoma patients treated with FEC or docetaxel-based regimens to check a) the usefulness of a biopsy after one course of chemotherapy to analyse survivin-3B expression, variation and ratio as well as survivin- $\Delta \mathrm{Ex} 3$ and survivin- $2 \mathrm{~B}$; and $\mathrm{b}$ ) the prognostic value of the survivin-3B transcript after one course of chemotherapy. These points may help to determine whether the continuation of treatment is beneficial for the patient.

\section{Acknowledgements}

This work was supported by the Conseil Régional de Bourgogne. We warmly thank Mary Bouley for her help in preparing the manuscript.

\section{References}

1. Ambrosini G, Adida C and Altieri DC: A novel anti-apoptosis gene, survivin, expressed in cancer and lymphoma. Nat Med 3: 917-921, 1997.

2. Li F, Ambrosini G, Chu EY, Plescia J, Tognin S, Marchisio PC and Altieri DC: Control of apoptosis and mitotic spindle checkpoint by survivin. Nature 396: 580-584, 1998.

3. Adida C, Crotty PL, McGrath J, Berrebi D, Diebold J and Altieri DC: Developmentally regulated expression of the novel cancer anti-apoptosis gene survivin in human and mouse differentiation. Am J Pathol 152: 43-49, 1998.

4. Xia F and Altieri DC: Mitosis-independent survivin gene expression in vivo and regulation by p53. Cancer Res 66: 3392-3395, 2006.

5. Altieri DC: Survivin in apoptosis control and cell cycle regulation in cancer. Prog Cell Cycle Res 5: 447-452, 2003.

6. Grossman D, Kim PJ, Blanc-Brude OP, et al: Transgenic expression of survivin in keratinocytes counteracts UVBinduced apoptosis and cooperates with loss of p53. J Clin Invest 108: 991-999, 2001.

7. Tamm I, Wang Y, Sausville E, Scudiero DA, Vigna N, Oltersdorf $\mathrm{T}$ and Reed JC: IAP-family protein survivin inhibits caspase activity and apoptosis induced by Fas (CD95), Bax, caspases, and anticancer drugs. Cancer Res 58: 5315-5320, 1998.

8. Verdecia MA, Huang H, Dutil E, Kaiser DA, Hunter T and Noel JP: Structure of the human anti-apoptotic protein survivin reveals a dimeric arrangement. Nat Struct Biol 7: 602-608, 2000.
9. Song Z, Yao X and Wu M: Direct interaction between survivin and Smac/DIABLO is essential for the anti-apoptotic activity of survivin during taxol-induced apoptosis. J Biol Chem 278: 23130-23140, 2003.

10. Giodini A, Kallio MJ, Wall NR, et al: Regulation of microtubule stability and mitotic progression by survivin. Cancer Res 62: 2462-2467, 2002.

11. Mahotka C, Wenzel M, Springer E, Gabbert HE and Gerharz CD: Survivin-deltaEx3 and survivin-2B: two novel splice variants of the apoptosis inhibitor survivin with different antiapoptotic properties. Cancer Res 59: 6097-6102, 1999.

12. Caldas H, Jiang Y, Holloway MP, Fangusaro J, Mahotka C, Conway EM and Altura RA: Survivin splice variants regulate the balance between proliferation and cell death. Oncogene 24: 1994-2007, 2005

13. You RI, Chen MC, Wang HW, Chou YC, Lin CH and Hsieh SL: Inhibition of lymphotoxin-beta receptor-mediated cell death by survivin-DeltaEx3. Cancer Res 66: 3051-3061, 2006.

14. Malcles MH, Wang HW, Koumi A, Tsai YH, Yu M, Godfrey A and Boshoff $\mathrm{C}$ : Characterisation of the anti-apoptotic function of survivin-DeltaEx3 during TNFalpha-mediated cell death. Br J Cancer 96: 1659-1666, 2007.

15. Krieg A, Mahotka C, Krieg T, et al: Expression of different survivin variants in gastric carcinomas: first clues to a role of survivin-2B in tumour progression. Br J Cancer 86: 737-743, 2002.

16. Badran A, Yoshida A, Ishikawa K, Goi T, Yamaguchi A, Ueda T and Inuzuka M: Identification of a novel splice variant of the human anti-apoptopsis gene survivin. Biochem Biophys Res Commun 314: 902-907, 2004.

17. Caldas H, Honsey LE and Altura RA: Survivin 2alpha: a novel Survivin splice variant expressed in human malignancies. Mol Cancer 2: 4-11, 2005.

18. Tanaka K, Iwamoto S, Gon G, Nohara T, Iwamoto M and Tanigawa N: Expression of survivin and its relationship to loss of apoptosis in breast carcinomas. Clin Cancer Res 6: 127-134, 2000.

19. Yamashita S, Masuda Y, Kurizaki T, Haga Y, et al: Survivin expression predicts early recurrence in early-stage breast cancer. Anticancer Res 27: 2803-2808, 2007.

20. Knauer SK, Krämer OH, Knösel T, Engels, et al: Nuclear export is essential for the tumor-promoting activity of survivin. FASEB J 21: 207-216, 2007.

21. Altieri DC: Survivin, cancer networks and pathway-directed drug discovery. Nat Rev Cancer 8: 61-70, 2008.

22. Hinnis AR, Luckett JC and Walker RA: Survivin is an independent predictor of short-term survival in poor prognostic breast cancer patients. Br J Cancer 96: 639-645, 2007.

23. Sohn DM, Kim SY, Baek MJ, Lim CW, Lee MH, Cho MS and Kim TY: Expression of survivin and clinical correlation in patients with breast cancer. Biomed Pharmacother 60: 289-292, 2006.

24. Kennedy SM, O'Driscoll L, Purcell R, Fitz-Simons N, McDermott EW, Hill AD, O'Higgins NJ, Parkinson M, Linehan R and Clynes M: Prognostic importance of survivin in breast cancer. Br J Cancer 88: 1077-1083, 2003.

25. Brennan DJ, Rexhepaj E, O'Brien SL, et al: Altered cytoplasmicto-nuclear ratio of survivin is a prognostic indicator in breast cancer. Clin Cancer Res 14: 2681-2689, 2008.

26. O'Driscoll L, Linehan R, Kennedy SM, et al: Lack of prognostic significance of survivin, survivin- $\Delta \mathrm{Ex} 3$, survivin-2B, galectin-3, bag-1, bax-a and MRP-1 mRNAs in breast cancer. Cancer Lett 201: 225-236, 2003.

27. Ryan B, O'Donovan N, Browne B, et al: Expression of survivin and its splice variants survivin- $2 \mathrm{~B}$ and survivin- $\triangle \mathrm{Ex} 3$ in breast cancer. Br J Cancer 92: 120-124, 2005.

28. Span PN, Tjan-Heijnen VC, Heuvel JJ, de Kok JB, Foekens JA and Sweep FC: Do the survivin (BIRC5) splice variants modulate or add to the prognostic value of total survivin in breast cancer? Clin Chem 52: 1693-1700, 2006.

29. Luporsi E, Vanlemmens L and Coudert B: Six cycles of FEC 100 vs six cycles of epirubicin/docetaxel as neoadjuvant chemotherapy in operable breast cancer patients: results of a randomized phase II trial of GIREC S01. Presented at the 36th Annual ASCO Meeting, Cancer Conf Highlights 4: 2-4, 2000.

30. Sataloff DM, Mason BA, Prestipino AJ, Seinige UL, Lieber CP and Baloch Z: Pathologic response to induction chemotherapy in locally advanced carcinoma of the breast: a determinant of outcome. J Am Coll Surg 180: 297-306, 1995. 
31. Arnal M, Franco N, Fargeot P, Riedinger JM, Brunet-Lecomte P and Lizard-Nacol S: Enhancement of mdrl gene expression in normal tissue adjacent to advanced breast cancer. Breast Cancer Res Treat 61: 13-20, 2000.

32. Livak KJ and Schmittgen TD: Analysis of relative gene expression data using real-time quantitative PCR and the 2(-Delta Delta C(T) method. Methods 25: 402-408, 2001.

33. Mercatante D and Kole R: Modification of alternative splicing pathways as a potential approach to chemotherapy. Pharmacol Ther 85: 237-423, 2000.

34. Mahotka C, Liebmann J, Wenzel M, Suschek CV, Schmitt M, Gabbert HE and Gerharz CD: Differential subcellular localization of functionally divergent survivin splice variants. Cell Death Differ 9: 1334-1342, 2002.

35. Horwitz SB: Taxol (paclitaxel): mechanisms of action. Ann Oncol 5 (Suppl 6): 3-6, 1994.
36. Knauer SK, Bier C, Schlag P, et al: The survivin isoform survivin-3B is cytoprotective and can function as a chromosomal passenger complex protein. Cell Cycle 6: 1502-1509, 2007.

37. Ling X, Yang J, Tan D, et al: Differential expression of survivin-2B and survivin-DeltaEx3 is inversely associated with disease relapse and patient survival in non-small-cell lung cancer (NSCLC). Lung Cancer 49: 353-361, 2005.

38. Mola G, Vela E, Fernández-Figueras MT, Isamat $M$ and Muñoz-Mármol AM: Exonization of Alu-generated splice variants in the survivin gene of human and non-human primates. J Mol Biol 366: 1055-1063, 2007. 